\title{
Epidemiology of seasonal and perennial rhinitis: clinical presentation and medical history
}

\author{
Bonnie Sibbald, Elizabeth Rink
}

\begin{abstract}
Background Little is known about the epidemiology of rhinitis, particularly the perennial and non-allergic forms. The aim of this study was to compare the symptoms, atopic state, and medical history of individuals with seasonal and perennial rhinitis.
\end{abstract}

Design Of 7702 adults aged $16-65$ years registered with a London general practice, $2969(30 \%)$ were screened by postal without rhinitis, 51 with seasonal symptoms alone, 128 with perennial symptoms alone, and 131 with perennial symptoms and seasonal exacerbations were then interviewed. Atopic and non-atopic subjects were distinguished by skinprick testing with five common allergens.

Results The estimated minimum prevalence of rhinitis was $24 \%: 3 \%$ had seasonal symptoms only, of whom $78 \%$ were atopic; $13 \%$ had perennial symptoms only, of whom $50 \%$ were atopic; and $8 \%$ had perennial symptoms with seasonal exacerbations, of whom $68 \%$ were atopic. Seasonal rhinitis was characterised by sneezing, itching, and a high prevalence of diurnal variation in symptoms. The most common provoking factors were dust, pollens, and infections. By comparison, perennial rhinitis was characterised by a higher prevalence of nasal blockage and catarrh, and a lower prevalence of diurnal variation and provocation by pollen. There were no significant differences among the groups in the sociodemographic characteristics examined. Subjects with seasonal rhinitis were more likely to be atopic and to have eczema and a family history of hayfever than those without rhinitis. Those with perennial rhinitis were more likely to have past or current eczema or migraine, be wheezy or labelled asthmatic, or have a family history of nose trouble other than hayfever. Subjects with both seasonal and perennial symptoms presented an intermediate clinical picture.

Department of Public Health Sciences, St George's Hospital Medical School, London SW17 ORE B Sibbald

E Rink

Reprint requests to: Dr Bonnie Sibbald, Department of General Practice and Primary Care, St George's Medical School, London SW 17 ORE

Accepted 12 August 1991 the diagnosis or classification of non-infectious questionnaire. Samples of 113 subjects

rhinitis. Rhinitis is characterised by chronic or recurrent sneezing and a runny or blocked nose, which may be either seasonal or perennial. It may be labelled "allergic," when a causative allergen is identified, or "nonallergic," when it is diviued according to whether or not nasal eosinophilia is present. ${ }^{1}$

Because identification of specific causative factors is not always practicable or possible, individuals are often classified as allergic or non-allergic according to their response to allergy skinprick testing. Although a positive skin test reaction does not necessarily indicate clinical sensitivity, there is a close association between cutaneous reactivity and serum concentrations of specific IgE. Positive skin test responses are generally regarded as evidence of an allergic or atopic constitution. ${ }^{1-4}$

Although rhinitis is common, surprisingly little is known about its epidemiology. Most research has focused on seasonal allergic rhinitis, in particular hayfever, leaving other forms of rhinitis unstudied. Estimates of the prevalence of hayfever vary from $2 \%$ to $15 \%$ according to the diagnostic criteria, method of investigation, and population studied. ${ }^{5-14}$ In the few studies where perennial rhinitis has been examined its prevalence was $2-3 \% .^{1112}$ As the prevalence of individuals with both hayfever and perennial rhinitis is also reported to be $2-3 \%,{ }^{58}$ the prevalence of perennial rhinitis has probably been underestimated.

Only one study has looked at the prevalences of both allergic and non-allergic rhinitis, and this was confined to schoolchildren and college students. ${ }^{10}$

The role of atopy in the epidemiology of rhinitis is ill defined. Hayfever, which is presumed to have an atopic basis, has a median age of onset of 15 years and a peak prevalence in people aged 16-24 years. ${ }^{815}$ In contrast, perennial rhinitis has a median age of onset of 20 years and reaches a peak prevalence in people of 20-30 years. ${ }^{16}$ It has been suggested that hayfever may be more prevalent among the upper social classes, ${ }^{817}$ firstborn children, ${ }^{17}$ children born in the spring, ${ }^{18} 19$ and those with a personal or family history of allergy. ${ }^{920}$

In an attempt to learn more about the epidemiology of rhinitis we conducted a postal questionnaire and interview survey among adults registered with a large group general practice in south west London. The findings relating to subjects' symptoms, atopic state, and medical history are presented here.

\section{Methods}

The study group consisted of all patients aged 
general practice in south west London. Eligible subjects were identified from the practice agesex register and asked to complete a postal screening questionnaire designed to identify those with rhinitis. Subjects were asked, "Do any of the following symptoms cause you trouble when you do not have a cold or the flu: sneezing/runny nose/blocked nose?" If any response was "yes" subjects were then asked, "For how many years have you had these symptoms: less than two years/two or more years?" Subjects were said to have rhinitis if they reported that they had had trouble with sneezing or a running or blocked nose for two or more years. Subjects were then asked to state whether symptoms were seasonal or perennial, and to rate the overall severity of their condition. Restricting the sample to people with symptoms for two or more years enabled us to obtain data on the seasonal or perennial nature of the symptoms.

Questionnaires were mailed in March, April, and May 1986, before the grass pollen season. The medical notes of a two in five sample of those who had not responded after two invitations were examined to ascertain the number of subjects whose current address differed from that on our mailing list. These data were used to provide an estimate of the numbers of subjects who received a questionnaire.

A stratified sample of those who completed the screening questionnaire were interviewed at home in June, July, and August about their symptoms, medical care, and possible risk factors for rhinitis. The aim was to interview 100 subjects in each of the following four groups: no rhinitis, seasonal symptoms alone, perennial symptoms alone, and perennial symptoms with seasonal exacerbations.

These groups were chosen to provide subjects from the widest possible range of disease. Subjects with rhinitis were further stratified according to the reported severity of their condition, so that subjects with the most severe symptoms would contribute half the sample. This stratification was carried out to maximise our ability to detect factors affecting the severity of rhinitis. Subjects who declined to be interviewed were replaced by others selected by the same sampling procedure.

At interview all subjects were asked about current nasal symptoms; allergic disease; demographic characteristics, including age, sex, occupation, and race; family history; type of bedding; pet ownership; and smoking and drinking. Subjects with rhinitis were also asked about nasal symptoms in the past 12 months; history of rhinitis, including provoking factors; disability; use of medical services; and drug treatment.

Allergy skinprick tests were carried out on all consenting subjects at the conclusion of the interview. Five allergens were used-house dust, house dust mite, mixed grass pollen, mixed tree pollen, and cat dander (Bencard)plus glycerol and histamine controls. A positive reaction was defined as a weal at least $3 \mathrm{~mm}$ larger than the glycerol control, in the presence of a reaction to the histamine control. Subjects with one or more positive reactions were defined as atopic and those with no positive reactions as non-atopic. The test was said to be invalid in subjects who failed to respond to the histamine control.

\section{ANALYSIS}

Similarities and differences in the clinical presentation of rhinitis were examined among subjects with seasonal, perennial, and seasonalperennial symptoms, and between atopic and non-atopic subjects within the three groups. The significance of differences between variables was assessed by the $\chi^{2}$ test for categorical variables and the Mann-Whitney $U$ test for continuously distributed variables.

Medical histories and sociodemographic characteristics were compared in subjects with and without rhinitis; in subjects with seasonal, perennial, and seasonal-perennial rhinitis; and in atopic and non-atopic subjects within each group. The findings are expressed as the odds that a subject with rhinitis will have a given medical history or sociodemographic characteristic. The odds ratio (OR) was calculated as the prevalence of the risk factor in those with rhinitis divided by its prevalence in those without. The $95 \%$ confidence interval $(\mathrm{CI})$ is given for each ratio.

\section{Results}

RESPONSE

Screening questionnaires were mailed to 7702 adults, of whom $2969(39 \%)$ returned usable questionnaires. Among the non-responders $113(1 \%)$ returned spoiled questionnaires, $1382(18 \%)$ had moved, and $3238(42 \%)$ failed to respond. Scrutiny of the medical records of a sample of 1372 non-responders showed that $413(30 \%)$ were at an address different from the one on our mailing list. This suggests that among the 3238 individuals who failed to respond around 971 (30\%) may not have received questionnaires. Removing these from the sample, plus those known to have moved, leaves 5349 subjects, of whom 2969 (56\%) returned a usable questionnaire.

Of the 2969 subjects who returned a usable questionnaire, 1309 (44\%) fulfilled our criteria for rhinitis. The assumptions that no nonresponders had rhinitis and that a population of 4391 subjects received the questionnaire gives a minimum prevalence of rhinitis in the population of $24 \%$ (1309/5249). Of the 1309 subjects with rhinitis, $142(11 \%)$ had seasonal symptoms only, $725(55 \%)$ had perennial symptoms only, and $442(34 \%)$ had perennial symptoms with seasonal exacerbations.

Four hundred and sixty six subjects were interviewed. There was agreement between the questionnaire and interview data for the diagnostic criteria for rhinitis in $443(95 \%)$ cases. Of the 342 subjects who fulfilled the criteria for rhinitis on the screening questionnaire, 330 $(96 \%)$ were found at interview to suffer from rhinitis; of the 124 subjects who did not fulfil the criteria for rhinitis on the screening questionnaire, $113(91 \%)$ were found at interview to be non-rhinitic.

Data analysis was confined to subjects whose 
questionnaire and interview responses were in agreement both in terms of the presence of rhinitis and of its seasonal or perennial nature. This sample comprised 113 subjects without rhinitis, 53 with seasonal symptoms alone, 129 with perennial symptoms alone, and 137 with perennial symptoms and seasonal exacerbations. Although our aim was to interview 100 subjects in each group there were insufficient subjects with only seasonal symptoms. We therefore increased the number of subjects interviewed in the other groups so that at least 300 rhinitic subjects were interviewed. The possible bias introduced by subjects' nonresponse was assessed by comparing the medical records of 100 non-responders and 100 participants. There were no significant differences between the groups for sex, marital status, or the proportion who drank alcohol; responders were significantly more likely than non-responders to be in one of the older age groups, to come from the upper social classes, and to be non-smokers.

\section{SKINPRICK TESTING (table 1)}

A valid skin test (that is, with a positive histamine control) was carried out in 51 subjects with seasonal rhinitis, 128 with perennial rhinitis, 131 with seasonal-perennial rhinitis, and 101 without rhinitis. The prevalence of atopy (as defined) was highest in those with seasonal rhinitis $(78 \%)$, intermediate in those with seasonal-perennial rhinitis $(71 \%)$, and lowest in those with perennial rhinitis only $(49 \%)$. The most common positive skin test response among those with seasonal rhinitis was to grass pollen, followed by house dust, cat dander, house dust mite, and tree pollen. Subjects with seasonal-perennial symptoms showed a similar pattern although the prevalence of a positive response to tree pollen was lower and of that to cat dander higher. Subjects with perennial symptoms alone resembled

Table 1 Skin test reactivity in subjects with and without rhinitis ${ }^{\star}$

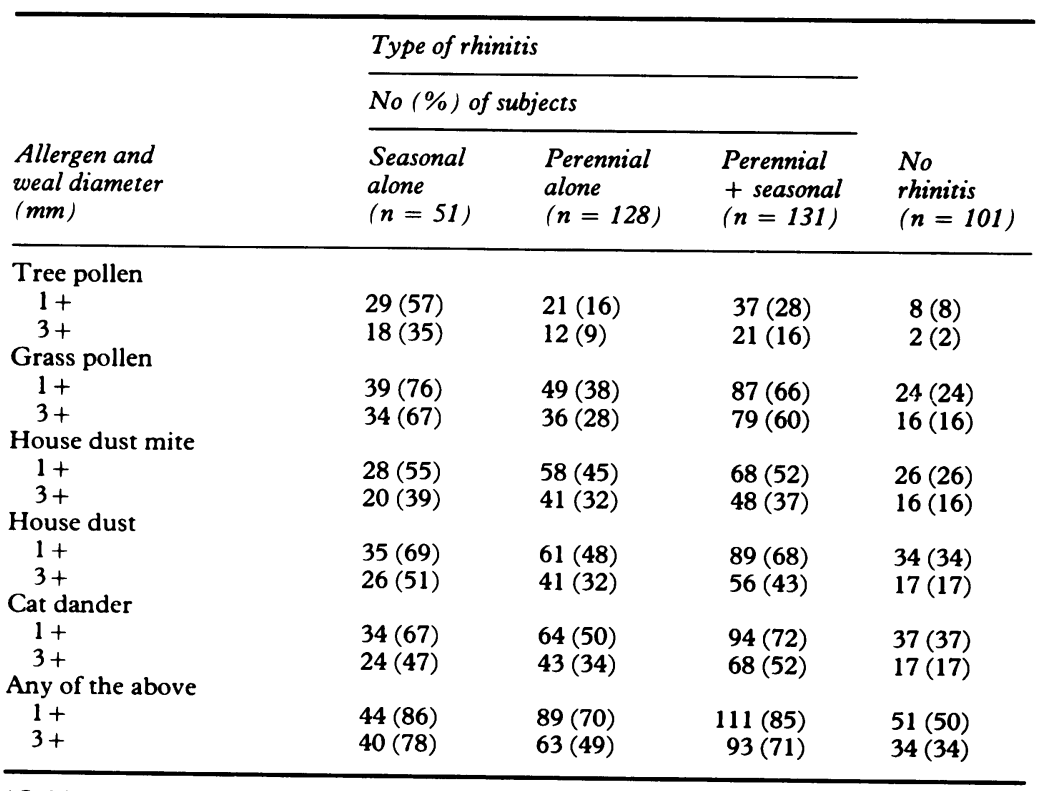

* Subjects who did not have a valid skin test (that is, with no positive histamine control) were excluded. subjects without rhinitis in the pattern of their skin test sensitivity, the prevalence of positive responses to house dust, house dust mite, cat dander, and grass pollen occuring with equal frequency (table 1).

\section{CLINICAL PRESENTATION AND NATURAL HISTORY} (table 2)

The median age at the onset of seasonal rhinitis was 18.5 years. Sneezing and itching were the most common presenting symptoms and most subjects experienced diurnal variation in symptoms. The most common provoking factors were dust, pollens, and colds and other infections.

The median age at the onset of perennial rhinitis (18.0 years) did not differ significantly from that of seasonal rhinitis. Nasal blockage and catarrh were more common presenting symptoms than in seasonal rhinitis, and diurnal variation occurred less frequently. Dust and colds or other infections were again common provoking factors, but pollen was less often reported.

Subjects with perennial symptoms and seasonal exacerbations presented an intermediate clinical picture. Sneezing, itching, and diurnal variation in symptoms were as prevalent as in subjects with seasonal rhinitis alone whereas nasal blockage was as prevalent as in perennial rhinitis alone. The most common provoking factors included dust, pollen, and colds or other infections. Seasonal-perennial rhinitis differed from other forms of rhinitis in having an earlier age of onset (14.0 years) and a higher prevalence of wheeze.

\section{CLINICAL PRESENTATION BY ATOPIC STATE \\ (table 3)}

The number of non-atopic subjects with seasonal rhinitis is very small (13); but the atopic subjects may have differed from the non-atopic subjects in having an earlier age at onset and a higher prevalence of sneezing and itchy eyes.

In perennial rhinitis there was no significant difference between atopic and non-atopic subjects in age at the onset of rhinitis. Atopic subjects differed from non-atopic subjects in having a lower prevalence of sinus headache and a higher prevalence of wheezing, and dust and pollen were provoking factors more frequently.

In the patients with seasonal-perennial rhinitis the atopic subjects had a lower median age at onset of rhinitis than non-atopic subjects and a higher prevalence of sneezing, itchy eyes, and itchy nose; and pollen and animals were more common provoking factors; foods and colds or other infections provoked rhinitis more frequently in the non-atopic group.

MEDICAL HISTORY (table 4)

Subjects with seasonal rhinitis were more likely to be atopic, to have current eczema, and to have a family history of hayfever than nonrhinitic subjects. Subjects with perennial rhinitis were not more likely to be atopic than those without rhinitis but were more likely to have a past or current history of eczema, to be wheezy or labelled asthmatic, to have a past or current 
Table 2 Clinical presentation of rhinitis

\begin{tabular}{|c|c|c|c|}
\hline \multirow[b]{3}{*}{ Factor } & \multicolumn{3}{|c|}{ Type of rhinitis } \\
\hline & \multicolumn{3}{|c|}{ No $(\%)$ of subjects } \\
\hline & $\begin{array}{l}\text { Seasonal } \\
\text { alone } \\
(n=53)\end{array}$ & $\begin{array}{l}\text { Perennial } \\
\text { alone } \\
(n=129)\end{array}$ & $\begin{array}{l}\text { Seasonal }+ \\
\text { perennial } \\
(n=137)\end{array}$ \\
\hline \multicolumn{4}{|l|}{ Age at onset (years) } \\
\hline Median & $18 \cdot 5$ & $18 \cdot 0$ & $14 \cdot 0^{\star}$ \\
\hline Range & $59 \cdot 0$ & $59 \cdot 0$ & $58 \cdot 0$ \\
\hline \multicolumn{4}{|c|}{ Principal symptoms (moderate or severe) } \\
\hline Sneeze & $31(58)$ & $71(55)$ & $91(66)$ \\
\hline Running nose & $23(43)$ & $67(52)$ & $84(61)$ \\
\hline Blocked nose & $25(47)$ & $82(64)$ & $94(69)^{\star}$ \\
\hline \multicolumn{4}{|l|}{ Other symptoms } \\
\hline Itchy eyes & $46(87)$ & $74(57)$ & $113(82)^{\star \star \star}$ \\
\hline Itchy nose & $39(74)$ & $67(52)$ & $87(64)^{\star}$ \\
\hline Itchy ear & $34(64)$ & $60(52)$ & $82(60)^{\star}$ \\
\hline Nose bleed & $12(23)$ & $28(22)$ & $40(29)$ \\
\hline Sinus headache & $21(40)$ & $64(50)$ & $65(47)$ \\
\hline Catarrh & $26(49)$ & $79(61)$ & $93(68)^{\star \star \star}$ \\
\hline Sore throat & $21(40)$ & $50(39)$ & $63(46)$ \\
\hline Wheezy chest & $12(23)$ & $34(26)$ & $60(44)^{\star}$ \\
\hline Diurnal variation in symptoms & $39(74)$ & $76(59)$ & $98(72)^{\star}$ \\
\hline \multicolumn{4}{|l|}{ Provoking factors } \\
\hline Dust & $40(76)$ & $87(67)$ & $108(79)$ \\
\hline Pollen & $39(74)$ & $34(26)$ & $83(61)^{\star \star \star}$ \\
\hline Animals & $11(21)$ & $12(9)$ & $42(31)^{\star \star \star}$ \\
\hline Food & $6(11)$ & $14(11)$ & $20(15)$ \\
\hline Alcoholic drinks & $5(9)$ & $12(9)$ & $7(5)$ \\
\hline Other drinks & $1(2)$ & $1(1)$ & $9(7)$ \\
\hline Colds and other infections & $33(62)$ & $90(70)$ & $111(81)^{\star}$ \\
\hline Fumes/perfumes & $29(55)$ & $46(36)$ & $72(53)^{\star \star}$ \\
\hline Change in air temperature & $26(49)$ & $53(41)$ & $78(57)^{\star}$ \\
\hline Smoky atmosphere & $23(43)$ & $57(44)$ & $52(38)$ \\
\hline Emotion & $5(10)$ & $14(20)$ & $37(27)^{\star \star \star}$ \\
\hline
\end{tabular}

Significance of differences among seasonal, perennial, and seasonal + perennial groups: ${ }^{\star} \mathrm{p}<0.05,{ }^{\star \star} \mathrm{p}<0.01,{ }^{\star \star \star} \mathrm{p}<0.001\left(\chi^{2}\right.$ test $)$.

Table 3 Clinical presentation of rhinitis according to presence or absence of atopy

\begin{tabular}{|c|c|c|c|c|c|c|}
\hline \multirow[b]{4}{*}{ Factor } & \multicolumn{6}{|c|}{ Type of rhinitis } \\
\hline & \multicolumn{6}{|c|}{ No $(\%)$ of subjects } \\
\hline & \multicolumn{2}{|l|}{$\begin{array}{l}\text { Seasonal } \\
\text { alone }\end{array}$} & \multicolumn{2}{|l|}{$\begin{array}{l}\text { Perennial } \\
\text { alone }\end{array}$} & \multicolumn{2}{|c|}{$\begin{array}{l}\text { Seasonal + } \\
\text { perennial }\end{array}$} \\
\hline & $\begin{array}{l}A \\
(n=40)\end{array}$ & $\begin{array}{l}N A \\
(n=13)\end{array}$ & $\begin{array}{l}A \\
(n=63)\end{array}$ & $\begin{array}{l}N A \\
(n=66)\end{array}$ & $\begin{array}{l}A \\
(n=93)\end{array}$ & $\begin{array}{l}N A \\
(n=44)\end{array}$ \\
\hline \multicolumn{7}{|l|}{ Age at onset (years) } \\
\hline $\begin{array}{l}\text { Median } \\
\text { Range }\end{array}$ & $\begin{array}{l}15 \cdot 5 \\
59 \cdot 0\end{array}$ & $\begin{array}{l}20 \cdot 0 \\
42 \cdot 0\end{array}$ & $\begin{array}{l}18 \cdot 5 \\
59 \cdot 0\end{array}$ & $\begin{array}{l}16 \cdot 5 \\
46 \cdot 0\end{array}$ & $\begin{array}{l}13 \cdot 0 \\
58.0\end{array}$ & $\begin{array}{l}16 \cdot 0^{\star} \\
58 \cdot 0\end{array}$ \\
\hline \multicolumn{7}{|l|}{$\begin{array}{l}\text { Principal symptom } \\
\text { (moderate or severe) }\end{array}$} \\
\hline $\begin{array}{l}\text { Sneeze } \\
\text { Other symptoms }\end{array}$ & $27(68)$ & $4(31)^{\star}$ & $36(57)$ & $35(53)$ & $70(75)$ & $21(48)^{\star \star}$ \\
\hline $\begin{array}{l}\text { Itchy eyes } \\
\text { Itchy nose } \\
\text { Sinus headache } \\
\text { Wheezy chest }\end{array}$ & $\begin{array}{l}37(93) \\
30(75) \\
15(38) \\
11(28)\end{array}$ & $\begin{array}{l}9(69)^{\star} \\
8(62) \\
6(46) \\
1(8)\end{array}$ & $\begin{array}{l}39(62) \\
32(51) \\
24(38) \\
23(37)\end{array}$ & $\begin{array}{l}35(53) \\
35(53) \\
40(61)^{\star} \\
11(17)^{\star}\end{array}$ & $\begin{array}{l}84(90) \\
66(71) \\
41(44) \\
45(48)\end{array}$ & $\begin{array}{l}29(66)^{\star \star \star} \\
21(48)^{\star \star} \\
24(54) \\
15(34)\end{array}$ \\
\hline \multicolumn{7}{|l|}{ Provoking factors } \\
\hline $\begin{array}{l}\text { Dust } \\
\text { Pollen } \\
\text { Animals } \\
\text { Food } \\
\text { Colds and other infections } \\
\text { Change in air temperature }\end{array}$ & $\begin{array}{r}32(80) \\
32(80) \\
9(23) \\
5(13) \\
22(55) \\
19(48)\end{array}$ & $\begin{array}{r}8(62) \\
7(54) \\
2(15) \\
1(8) \\
11(85) \\
7(54)\end{array}$ & $\begin{array}{r}48(76) \\
22(35) \\
9(14) \\
8(13) \\
43(68) \\
31(49)\end{array}$ & $\begin{array}{l}39(59)^{\star} \\
12(18)^{\star} \\
3(5) \\
6(9) \\
47(71) \\
22(33)\end{array}$ & $\begin{array}{l}75(81) \\
71(76) \\
35(38) \\
8(9) \\
71(76) \\
47(51)\end{array}$ & $\begin{array}{l}33(59) \\
12(27)^{\star \star \star} \\
7(16)^{\star} \\
12(27)^{\star \star} \\
40(91)^{\star} \\
31(70)^{\star}\end{array}$ \\
\hline
\end{tabular}

Significance of differences between atopic and non-atopic subgroups: ${ }^{\star} p<0.05$ $\star \star p<0.01, \star \star \star p<0.001$ ( $\chi^{2}$ test).

A-atopic; NA-non-atopic.

history of migraine, and to have a family history of nose trouble other than hayfever. Subjects with seasonal-perennial rhinitis again presented an intermediate clinical picture, being more likely to be atopic, to have a past or current history of eczema, to have a past or current history of wheeze, to be labelled asthmatic, and to have a famiy history of hayfever or other nose trouble than subjects without rhinitis.

MEDICAL HISTORY BY ATOPIC STATE (table 5)

Subjects with atopic seasonal rhinitis were more likely than subjects without rhinitis to have a history of eczema and a family history of hayfever, though only the latter difference was significant. The findings in non-atopic subjects are limited by the small sample size, but suggest that non-atopic subjects are also more likely than non-rhinitic subjects to have current eczema and a family history of hayfever.

In perennial rhinitis atopic subjects more often had a history of eczema and current migraine, were labelled asthmatic, and had a family history of rhinitis than subjects without rhinitis, though not all differences were significant. In contrast, non-atopic subjects were more likely than non-rhinitic subjects to have current migraine, but were not at increased risk for the other factors examined.

Among the subjects with seasonal-perennial rhinitis the atopic subjects were more often labelled asthmatic than non-rhinitic subjects and both atopic and non-atopic subjects more often had a history of eczema and wheeze and a family history of rhinitis, though not all differences were significant.

\section{SOCIODEMOGRAPHIC AND OTHER}

\section{CHARACTERISTIC}

There were no significant differences between subjects with seasonal, perennial, and seasonalperennial rhinitis in any of their sociodemographic characteristics, including age, sex, race, country of birth, birth order, maternal age at birth, marital status, employment status, social class, school leaving age, smoking history, drinking history, pet ownership, or feather bedding.

When compared with the non-rhinitic subjects, subjects with seasonal rhinitis were less likely than those without rhinitis to have a smoker in the household (OR 0.51, $95 \%$ CI $0.27-0.96)$ and subjects with seasonalperennial symptoms were more likely to come from the upper social classes (OR 1.37, 95\% CI 1.02-1.84). Noother significant differences were found between any of the rhinitic groups and the non-rhinitic subjects.

\section{Discussion}

In interpreting and extrapolating the results we have to bear in mind that this study was conducted among patients registered with a single general practice in south west London, and as such may not be representative of people with rhinitis elsewhere. An added difficulty is that response rates were low, allowing us to establish only approximate minimum prevalence rates. The sample of rhinitic subjects selected for detailed study was stratified by the seasonality and severity of symptoms so that the widest possible range of disease would be represented. This is unlikely to have seriously biased the comparison between the different forms of rhinitis, or the analysis of risk factors.

No simple objective method was available for 
Table 4 Medical history of subjects with rhinitis compared with that of subjects without rhinitis

\begin{tabular}{|c|c|c|c|}
\hline \multirow[b]{3}{*}{ Medical history } & \multicolumn{3}{|l|}{ Type of rhinitis } \\
\hline & \multicolumn{3}{|c|}{ Odds ratio ${ }^{\star}$ ( $95 \%$ confidence interval) } \\
\hline & $\begin{array}{l}\text { Seasonal } \\
\text { alone } \\
(n=53)\end{array}$ & $\begin{array}{l}\text { Perennial } \\
\text { alone } \\
(n=129)\end{array}$ & $\begin{array}{l}\text { Seasonal }+ \\
\text { perennial } \\
(n=137)\end{array}$ \\
\hline $\begin{array}{l}\text { Atopic } \\
\text { Eczema }\end{array}$ & $1.62(1.18-2 \cdot 23)$ & $1.05(0.81-1.36)$ & $1.46(1 \cdot 18-1 \cdot 81)$ \\
\hline $\begin{array}{l}\text { Ever } \\
\text { In past year }\end{array}$ & $\begin{array}{l}1.84(0.84-4.05) \\
3.00(1.22-7.34)\end{array}$ & $\begin{array}{l}2.02(1.20-4.03) \\
3.45(1.63-7.27)\end{array}$ & $\begin{array}{l}2.92(1.65-5.19) \\
2.78(1.30-5.96)\end{array}$ \\
\hline $\begin{array}{l}\text { Wheeze } \\
\text { Ever } \\
\text { Labelled asthma } \\
\text { In past year }\end{array}$ & $\begin{array}{l}0.63(0.33-1.21) \\
1.60(0.46-5.53) \\
1.41(0.67-2.96)\end{array}$ & $\begin{array}{l}1 \cdot 17(0 \cdot 82-1 \cdot 66) \\
3 \cdot 12(1 \cdot 29-7 \cdot 55) \\
1 \cdot 91(1 \cdot 12-3 \cdot 25)\end{array}$ & $\begin{array}{l}1 \cdot 71(1 \cdot 25-2 \cdot 23) \\
4 \cdot 48(1 \cdot 93-10 \cdot 42) \\
3 \cdot 11(1 \cdot 92-5 \cdot 04)\end{array}$ \\
\hline $\begin{array}{l}\text { Migraine } \\
\text { Ever } \\
\text { In past year } \\
\text { Other medical problems }\end{array}$ & $\begin{array}{l}1.31(0.68-2.51) \\
0.67(0.03-1.50)\end{array}$ & $\begin{array}{l}1.45(1.02-2.05) \\
1.73(1.13-2.65)\end{array}$ & $\begin{array}{l}1.08(0.75-1.57) \\
1.11(0.70-1.78)\end{array}$ \\
\hline $\begin{array}{l}\text { Broken nose ever } \\
\text { Nasal polyp ever } \\
\text { Depression ever } \\
\text { Family history }\end{array}$ & $\begin{array}{l}0 \cdot 16(0.02-1 \cdot 19) \\
2 \cdot 40(0 \cdot 15-37 \cdot 90) \\
0.66(0 \cdot 31-1 \cdot 39)\end{array}$ & $\begin{array}{l}0.72(0.35-1.51) \\
5.91(0.72-48.37) \\
1.12(0.73-1.73)\end{array}$ & $\begin{array}{l}0.74(0.36-1.52) \\
3.71(0.42-32 \cdot 72) \\
1.12(0.73-1.71)\end{array}$ \\
\hline $\begin{array}{l}\text { Hayfever } \\
\text { Other nose trouble } \\
\text { Asthma }\end{array}$ & $\begin{array}{l}2 \cdot 25(1 \cdot 16-4 \cdot 35) \\
1 \cdot 27(0 \cdot 59-2 \cdot 74) \\
1 \cdot 44(0.54-3 \cdot 84)\end{array}$ & $\begin{array}{l}1.23(0.67-2.26) \\
1.80(1.05-3.07) \\
1.38(0.64-2.99)\end{array}$ & $\begin{array}{l}2 \cdot 20(1.30-3.74) \\
2 \cdot 78(1.70-4.54) \\
1.95(0.96-3.97)\end{array}$ \\
\hline
\end{tabular}

*Odds ratio: the prevalence of a medical history variable in subjects with rhinitis divided by that in non-rhinitic subjects (significant odds ratios in bold type).

identifying and assessing rhinitis for epidemiological purposes. We therefore defined rhinitis as a self reported problem with sneezing, runny nose, or blocked nose that was not solely associated with upper respiratory tract infection and had persisted for two or more years. The high level of agreement between the questionnaire and interview findings suggests that these questionnaire criteria were highly sensitive and reasonably specific in identifying subjects who reported symptoms of rhinitis at interview.
The minimum prevalence of rhinitis among adults aged 16-65 years in this south west London community appears to be $24 \%$, consisting of $3 \%$ with seasonal symptoms only, $13 \%$ with perennial symptoms only, and $8 \%$ with perennial symptoms with seasonal exacerbations. These prevalence figures are generally higher than previously supposed, ${ }^{5-14}$ particularly for perennial rhinitis. The overall prevalence of seasonal rhinitis in our study was $11 \%$ (3\% with seasonal symptoms only plus $8 \%$ with seasonal-perennial symptoms), which is similar to the estimated prevalence of $10 \%$ for hayfever in Britain. ${ }^{11}$ The previously reported prevalence of perennial rhinitis $(3 \%)^{12}$ is substantially lower than our prevalence of $21 \%$ ( $13 \%$ with perennial symptoms alone plus $8 \%$ with seasonal-perennial symptoms).

These differences in prevalence may be attributed in part to the focus in previous studies on the prevalence of physician diagnosed rhinitis among consulting patients. 'This approach excludes subjects who do not seek medical help or whose rhinitis is unrecognised by the physician. Individuals with rhinitis who have seasonal symptoms are nearly twice as likely as those with perennial symptoms to be labelled as having rhinitis by the general practitioner. ${ }^{11}$ The present study avoids the bias inherent in studying diagnosed diseases by measuring the prevalence of symptoms of rhinitis among unselected subjects in the community.

Atopy was assessed by skinprick testing with five common aeroallergens. These allergens identify over $95 \%$ of subjects who would react to a much larger battery of allergens. ${ }^{14}$ Increasing the range of allergens would not therefore have increased the proportion designated atopic appreciably. The selection of a weal of

Table 5 Medical history according to presence or absence of atopy in subjects with rhinitis compared with that of subjects without rhinitis

\begin{tabular}{|c|c|c|c|c|}
\hline \multirow[b]{3}{*}{ Medical history } & \multirow[b]{3}{*}{$\begin{array}{l}\text { Atopic } \\
\text { state }\end{array}$} & \multicolumn{3}{|l|}{ Type of rhinitis } \\
\hline & & \multicolumn{3}{|c|}{ Odds ratio ${ }^{\star}$ ( $95 \%$ confidence interval) } \\
\hline & & $\begin{array}{l}\text { Seasonal alone } \\
(n=53)\end{array}$ & $\begin{array}{l}\text { Perennial alone } \\
(n=129)\end{array}$ & $\begin{array}{l}\text { Seasonal + perennial } \\
(n=137)\end{array}$ \\
\hline \multicolumn{5}{|l|}{ Eczema } \\
\hline $\begin{array}{l}\text { Ever } \\
\text { In past year }\end{array}$ & $\begin{array}{l}\text { Atopic } \\
\text { Non-atopic } \\
\text { Atopic } \\
\text { Non-atopic }\end{array}$ & $\begin{array}{l}6.80(0.90-511.46) \\
1.05(0.24-4.65) \\
6.80(0.90-51.46) \\
2 \cdot 11(0.42-10.54)\end{array}$ & $\begin{array}{l}7.56(1.05-54.30) \\
1.80(0.86-3.75) \\
5.40(0.73-39.88) \\
1.44(0.46-4.51)\end{array}$ & $\begin{array}{c}10.60(1.53-73.48) \\
2 \cdot 15(0.99-4 \cdot 70) \\
5.85(0.82-41.68) \\
2.87(0.98-8.40)\end{array}$ \\
\hline \multicolumn{5}{|r|}{$2.87(0.90-0.40)$} \\
\hline $\begin{array}{l}\text { Ever } \\
\text { Labelled asthma } \\
\text { In past year }\end{array}$ & $\begin{array}{l}\text { Atopic } \\
\text { Non-atopic } \\
\text { Atopic } \\
\text { Non-atopic } \\
\text { Atopic } \\
\text { Non-atopic }\end{array}$ & $\begin{array}{l}0.99(0.54-1.82) \\
1.52(0.66-3.51) \\
0.85(0.13-5.69) \\
3.04(0.57-16.12) \\
0.99(0.37-2.65) \\
1.82(0.52-6.12)\end{array}$ & $\begin{array}{l}1.66(1.07-2.60) \\
1.40(0.89-2 \cdot 18) \\
4 \cdot 05(1.00-16.36) \\
1.23(0.32-4.76) \\
1.89(0.87-4.09) \\
1.25(0.57-2.72)\end{array}$ & $\begin{array}{l}1.80(1.21-2.68) \\
1.80(1.12-2 \cdot 88) \\
4 \cdot 75(1.22-18 \cdot 47) \\
1.35(0.31-5 \cdot 82) \\
2 \cdot 38(1 \cdot 16-4 \cdot 86) \\
3 \cdot 23(1.59-6.56)\end{array}$ \\
\hline \multicolumn{5}{|l|}{ Migraine } \\
\hline $\begin{array}{l}\text { Ever } \\
\text { In past year }\end{array}$ & $\begin{array}{l}\text { Atopic } \\
\text { Non-atopic } \\
\text { Atopic } \\
\text { Non-atopic }\end{array}$ & $\begin{array}{l}0.85(0.33-2.16) \\
1.06(0.38-2.92) \\
1.02(0.34-3.03) \\
0.41(0.05-2.99)\end{array}$ & $\begin{array}{l}1.93(0.97-3.84) \\
1.46(0.92-2.30) \\
2.05(0.87-4.86) \\
1.99(1.14-3.49)\end{array}$ & $\begin{array}{l}1.41(0.71-2.99) \\
1.17(0.66-2.07) \\
1.46(0.62-4.35) \\
1.20(0.57-2.50)\end{array}$ \\
\hline $\begin{array}{l}\text { Family history } \\
\text { Hayfever } \\
\text { Other nose trouble }\end{array}$ & $\begin{array}{l}\text { Atopic } \\
\text { Non-atopic } \\
\text { Atopic } \\
\text { Non-atopic }\end{array}$ & $\begin{array}{l}3.40(1.05-10.98) \\
2 \cdot 28(0.63-8.28) \\
1.49(0.48-4.62) \\
1.22(0.28-5.37)\end{array}$ & $\begin{array}{l}2.52(0.80-7.98) \\
0.90(0.33-2.47) \\
2.29(0.86-6.11) \\
1.68(0.70-3.54)\end{array}$ & $\begin{array}{l}3.53(1 \cdot 19-10.51) \\
2.02(0.82-4.97) \\
3.11(1.24-7 \cdot 80) \\
3.05(1.49-6 \cdot 25)\end{array}$ \\
\hline
\end{tabular}

*Odds ratio: the prevalence of a medical history variable in subjects with rhinitis divided by that in subjects without rhinitis (significant odds ratios in bold type). 
$3 \mathrm{~mm}$ or more in diameter as the criterion for positivity is arbitrary, but is widely used.

The prevalence of atopy among subjects with rhinitis was highest in those with seasonal symptoms and lowest in those with perennial symptoms only. Seasonal rhinitis, particularly hayfever, is thought to be caused by type 1 hypersensitivity to grass or tree pollen or both, whereas perennial rhinitis is thought to be caused by both allergic and non-allergic mechanisms, type 1 hypersensitivity to dust or animals characterising the allergic form. In keeping with this hypothesis we found that the prevalence of tree pollen sensitivity was lower and cat dander sensitivity higher in those with perennial symptoms than in those with seasonal symptoms; indeed, pollen sensitivity in general was reported less often by those with perennial symptoms only. Dust was the most commonly reported provoking factor in all groups of subjects with rhinitis.

Only three quarters of our subjects with seasonal rhinitis were atopic by our criteria. Possible reasons for this include our method of defining atopy as described above or the localisation of sensitivity to the nasal mucosa alone in some individuals. Type 1 hypersensitivity may not underlie all forms of seasonal rhinitis.

As in previous studies, seasonal rhinitis was characterised by sneezing and itchy eyes or nose, whereas perennial rhinitis was characterised by nasal blockage. The exent to which the clinical presentation is influenced by the subject's atopic state is not clear. Sneezing and itching appeared to be more closely associated with atopy than with the seasonal nature of their symptoms, whereas nasal blockage was associated with perennial symptoms more than with atopy or its absence.

A family history of rhinitis was a risk factor for both seasonal and perennial rhinitis. The increased prevalence of a family history of hayfever, but not "other nose trouble," among subjects with seasonal symptoms alone, while the reverse was true among subjects with perennial symptoms alone, suggests that genetic factors may determine both the presence of rhinitis and its seasonal or perennial nature. Alternatively, this could arise from reporting bias as subjects are likely to recognise conditions similar, rather than dissimilar, to their own among family members. Appropriate family studies are needed to investigate the hereditary basis of seasonal and perennial rhinitis and the extent to which this is shared.

Current eczema was a more important risk factor than past eczema for both seasonal and perennial rhinitis. The same appears true for asthma. Data from the National Child Development Study, a prospective study of 17414 children followed from birth to 23 years, has shown that current eczema, but not past eczema, is an important risk factor for wheezing illness (H R Anderson, personal communication). These findings raise the possibility that the conditions either have a common underlying pathological process or are provoked by a common external agent.

A history of past and current migraine was more prevalent among subjects with perennial symptoms than among those with seasonal symptoms alone. Previous studies have shown that headache and nausea may accompany asthma, ${ }^{22}$ but their occurrence in rhinitis has not been reported previously. The symptoms we labelled as migraine-namely, headache accompanied by disturbed vision or nauseacould have been caused by sinus infection. The findings showed that both sinus headache and infection as provoking factors tended to be more prevalent in subjects with non-atopic and perennial rhinitis. Whether migraine is genuinely more common among people with rhinitis therefore remains unclear.

Several factors have previously been reported to influence the risk of rhinitis, but were not found to do so here. These included birth order, maternal age at birth, and social class. ${ }^{817}$ We have shown that people from the upper social classes are more likely than those from the lower social classes to be labelled as having hayfever, though there are no significant differences between social classes in the prevalence of hay fever as determined by symptoms and skin test responses to grass pollen. ${ }^{21}$ This bias might also explain the reported association of rhinitis with birth order and maternal age at birth as both these factors are related to family size, which in turn varies with social class.

Although much remains unknown about the epidemiology of rhinitis, the principal question must be whether the seasonal and perennial forms have the same or a different aetiology. The prevalence of individuals with both perennial and seasonal symptoms is higher than would be expected by chance alone. This suggests that there is a common factor underlying all forms of rhinitis, though its existence and nature are uncertain. By analogy with asthma, perhaps the two forms of rhinitis have a common genetic basis but atopy modifies the way in which this is expressed. ${ }^{24}$ An in depth analysis of our data is planned to assess the relative importance of atopy and other factors in determining the type and distribution of symptoms in rhinitis. Family studies will also be needed to assess the genetic basis of rhinitis and its relation to atopy.

We would like to thank the Medical Research Council for its support of this work, the doctors of the Brocklebank Health Centre for giving us access to their patients, and the patients themselves for their kind cooperation. Our thanks also go to Crof the work.

1 Mygind N. Nasal allergy. 2nd ed. Oxford: Blackwell, 1979:219-21, 224-25.

2 Pepys J. Skin testing. Br J Hosp Med 1975;14:412-7.

3 Eriksson NE. Allergy screening in asthma and allergic rhinitis. Allergy 1987;42:189-95

4 Merrett TG, Pantin CFA, Dimond AH, Merrett J. Screening for IgE-mediated allergy. Allergy 1980;35:491-501.

5 van Ardsel PP, Motulsky AG. Frequency and heritability of asta Genet 1959;9:101-14.

6 Edfors-Lubs ML. Allergy in 7000 Twin pairs. Acta Allerg $1971 ; 26: 249-85$.

7 Coffman D, Chalmers CP. Incidence of hayfever in a North London practice. J R Coll Gen Pract 1974;24:171-80.

8 Broder I, Higgins MW, Matthews KP, Keller JP. Epidemiology of asthma and allergic rhinitis in a tota community, Tecumseh, Michigan. III. Second survey of ome clin Immunol 1974;53:127-38. 
9 Burrows B, Lebowitz MD, Barbee RA. Respiratory disorders and allergy skin test reactions. Ann Intern Med 1976;84:134-9.

10 Malmberg H. Symptoms of chronic and allergic rhinitis and occurrence of nasal secretion granulocytes in university students, school children and infants. Allergy 1979; 34:389-94.

11 Rose A. Chronic illness in a general practice. Family Practice 1984;1:162-7.

12 Sibbald B, Tooley $M$. Survey of perennial rhinitis in a SW London general practice. In: Svendsen U, Weeke B, eds. Histaminer og antihistaminer. Janssen Pharmaceutical Publication, 1985:125-31.

13 Fleming DM, Crombie DL. Prevalence of asthma and hayfever in England and Wales. BMJ 1987;294:279-83.

14 Weeke ER. Epidemiology of hayfever and perennial allergic rhinitis. Monogr Allergy 1987;21:1-20.

15 Schachter J, Higgins MW. Median onset age of asthma and allergic rhinitis in Tecumseh, Michigan. J Allergy Clin Immunol 1976;54:342-51.

16 Viner AS, Jackman N. Retrospective survey of 1271 patients diagnosed as perennial rhinitis. Clin Allergy 1976;6:251-9. 17 Taylor B, Wadsworth J, Golding J, Butler N. Breast feeding, eczema, asthma and hayfever. J Epidemiol Commun Health 1983;37:95-9.

18 Korsgaard J, Dahl R. Sensitivity to house dust mite and pollen in adults. Influence of month of birth. Clin Allergy 1983;13:528-36.

19 Aberg N. Birth season variation in asthma and allergic rhinitis. Clin Exp Allergy 1989;19:643-8.

20 Gerrard JW, Vickers P, Gerrard CD. The familial incidence of allergic disease. Ann Allergy 1976;36:10-5.

21 Sibbald B, Rink E. Labelling of rhinitis and hayfever by doctors. Thorax 1991;46:378-81.

22 Shneerson J. Non-respiratory symptoms of acute asthma. Thorax 1986;41:701-2.

23 Anderson HR, Bland JM, Patel S, Peckham C. The natural history of asthma in childhood. J Epidemiol Commun Health 1986;40:121-9.

24 Sibbald B. Genetic basis of asthma. Semin Respir Med 1986;7:307-15. 